\title{
Psychotherapy training experience in an inner-city psychiatry rotation
}

\section{AIMS AND METHOD}

A postal questionnaire was circulated

to all psychiatrists who had completed their basic specialist training on the Royal London Hospital training scheme within the last 7.5 years. The aim of the questionnaire was to explore their psychotherapy experience while on the rotation.

\section{RESULTS}

The response rate was $95 \%$. The respondents had a broad experience of both didactic and case work that they valued highly. Over half of them wished for an even greater exposure to psychotherapy during their basic training.

\begin{abstract}
CLINICAL IMPLICATIONS
The results of our survey suggest that with the dedication of both the trainees and trainers, it is possible to have a comprehensive psychotherapy experience while working on a busy inner-city rotation.
\end{abstract}

The Royal College of Psychiatrists has continued to emphasise the importance of psychotherapy training in different psychological modalities. The College guidelines for psychotherapy training as part of general professional training were published in 1993 (Grant et al, 1993). The new requirements, which follow on from the guidelines, have been prepared by the Psychotherapy and General Psychiatry Faculties. These requirements (still unpublished) have been agreed on, in principle, to become mandatory and only the implementation details are still under negotiation. These will depend largely on the results of the audit of candidates taking the MRCPsych exam in May 2001. The requirements were distributed to clinical tutors and Consultant Psychiatrists in summer 2001, with a covering letter from the Dean, Prof C. Katona.

They focus on five major areas, under the following headings:

1. Development of interview skills

2. Psychotherapeutic formulation

3. A minimum of three short-term cases, each using a different psychotherapeutic model

4. One long-term individual case

5. Some experience of either group therapy or couple, family and systemic therapy.

Previous studies comparing the recommendations from 1993 with practice (Hamilton \& Tracy, 1996; Hwang \& Drummond, 1996; Byrne \& Meagher, 1997; Rooney \& Kelly, 1999) have commonly found training not fulfilling the 1993 guidelines, with widespread shortcomings of psychotherapy training, lack of opportunities to take on cases and deficits in didactic teaching. These studies have recommended improvements; especially in the availability and quality of the psychotherapy supervision, ring-fenced time for the training and widening of the range of modalities. As far as we are aware, no study assessing psychotherapy training on an inner-city training scheme has been undertaken.

The aim of this study was to assess the training in psychotherapy among those trainees who successfully concluded their basic specialist training by passing the Membership Exam (MRCPsych) while on a Royal London Hospital (RLH) training scheme in psychiatry, subsequently incorporated into RLH and St Bartholomew's Hospital training scheme. A subsidiary aim was to assess the perceived relevance of the above mentioned psychotherapy experience in the respondents' current jobs.

\section{Method}

\section{Setting}

The rotation comprises three main teaching hospitals (RLH (St Clements Hospital), East Ham Memorial Hospital and Goodmayes Hospital), with some satellite jobs (mainly including child psychiatry, learning disabilities and some of the old age and general adult settings). The majority of the jobs (24-25 in total) are very busy innercity posts, serving a diverse population from varying ethnic, racial and linguistic backgrounds, with one of the highest levels of deprivation in the country as shown by Jarman scores. The three different levels of development of psychological treatment services have been described in the recent 'requirements' document:

1. Level 1 - described as a specialist psychological service with a Consultant Psychotherapist and other specialist staff:

2. Level 2 - a Consultant Psychotherapist working with some other specialist practitioners, but lacking specialist skills available for all training requirements;

3. Level 3 - no specialist facilities available, no Consultant Psychotherapist and limited psychological treatment services.

The rotation presents a mixed picture according to this classification; with one hospital having a dedicated psychotherapy department with two part-time consultants (which will probably fulfil criteria for level 1), while the other two centres are at level 3. 


\section{Subjects}

original

Twenty-four individuals who were trainees on the scheme and passed their Part II exam between 1993 and spring 2001 were identified.

\section{Questionnaire}

A questionnaire was devised and sent to all eligible respondents. The questionnaire was divided into four sections, covering demographic data, psychotherapy training and experience as a senior house officer ( $\mathrm{SHO}$ ), and some miscellaneous questions. There was also an opportunity for specific comments.

\section{Results}

Out of 24 originally identified subjects, 23 were eligible (sadly, one of our colleagues passed away last year), and these individuals were sent the questionnaires in autumn 2001. Twenty-two replies were received, giving a response rate of $95 \%$. Most of the respondents received their basic medical training in UK (80\%), some in Ireland $(10 \%)$, some in Australia (5\%) and some in the Middle
East (5\%). Gender was represented equally. Plans for the future and current consultant posts of respondents include the following specialties: adult (35\%), child (27\%), forensic $(5 \%)$, forensic psychotherapy $(5 \%)$, old age $(23 \%)$ and addictions ( $5 \%)$. The details in psychotherapy training are presented in Table 1.

Forty-five per cent of trainees recalled having an introductory session on psychotherapy; $14 \%$ who answered 'don't know' passed their exam in 1993-95 and gave an explanation of not remembering such minute details.

The majority (91\%) of respondents recalled having theoretical seminars and $95 \%$ of this group attended them.

Eighty-six per cent reported having access to case presentation psychotherapy seminars and $89 \%$ of those attended them.

The training in assessment for suitability for various treatments was also assessed; while $64 \%$ of respondents remembered receiving such teaching, only $64 \%$ of this group judged it as very good or good.

Ninety-one per cent recalled having a psychotherapyorientated support group; $65 \%$ found it helpful, while $35 \%$ felt that it 'wasn't enough'.

Table 1. Details of psychotherapy training during basic specialist training

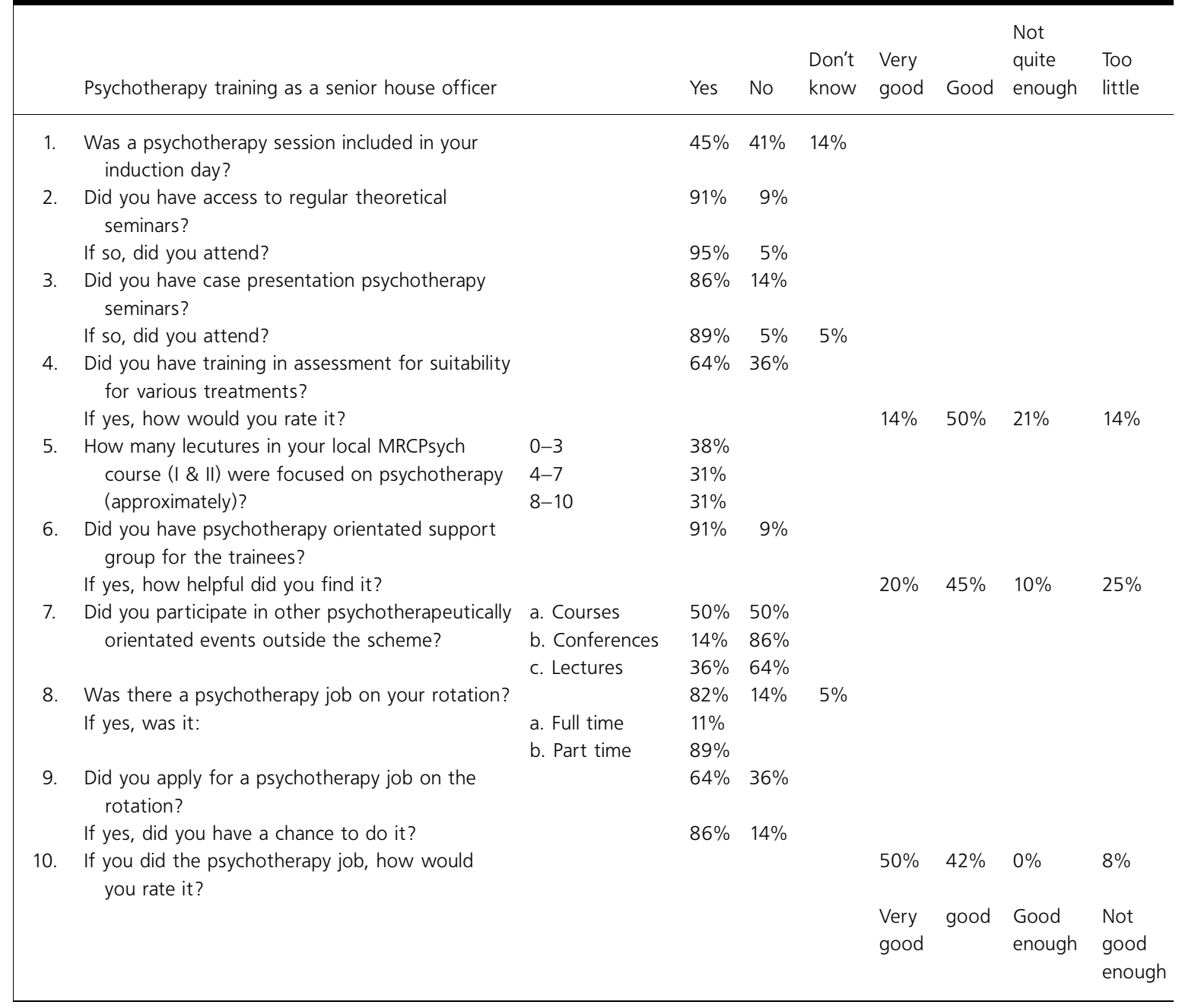


With regards to a dedicated 6 -month post in psychotherapy, the majority of those who applied for it had the opportunity to work in this post and $92 \%$ of those rated it as very good or good (this is a 'split post', shared with child psychiatry and more recently, rehabilitation psychiatry).

The details of clinical psychotherapy experience are detailed in Table 2. Ninety-five per cent of trainees had an opportunity to take on a long case and some trainees, mostly those who worked in the psychotherapy post for 6 months, had treated more than one case. The duration of those cases varied, with the majority lasting over 26 weeks (85\%) and one case lasting 8 years. With regards to the quality of supervision, it was mostly weekly (76\%), with a Consultant Psychotherapist/Psychiatrist or a non-medical Psychotherapist and $75 \%$ judged it as excellent/good.

Among short cases, cognitive-behavioural therapy was most popular, with $73 \%$ of respondents having an experience of it and $75 \%$ of this group treating more than one case. The majority of trainees were supervised by a psychologist in this modality. The quality of supervision was rated very highly; $81 \%$ thought it excellent/good.

Family and marital therapy was conducted most commonly in the setting of child and adolescent psychiatry, with most supervision from the Consultant Child Psychiatrist and, once again, it was judged highly by the trainees. Almost half of respondents also had a chance to experience group therapy (45\%); most likely a reflection of a special interest in this subject of one of the consultants.

Cognitive-analytical therapy was one of the less frequently-experienced modalities; it is only available at the psychotherapy department and mostly to the trainees doing a psychotherapy job. Brief focal psychotherapy was experienced by only $32 \%$. It was mostly supervised by a Consultant Psychiatrist, usually on a weekly basis and supervision was rated as excellent/good in $86 \%$ of cases. As the psychotherapy department was joined last year by a part time consultant with a special interest in this modality, it is expected to become more popular among trainees in the future.

In the last part of the questionnaire, under the heading of Miscellaneous Questions, the relevance of the training to current jobs was examined. Fifty-five per cent of respondents judged it as very relevant and $23 \%$ as relevant. None of them thought that there was too much emphasis on psychotherapy and $54 \%$ wished for more psychotherapy experience.

\section{Discussion}

Until recently, the rotation was geographically fairly limited, with a small number of trainees; this accounted

Table 2. Details of psychotherapy experience during basic specialist training

\begin{tabular}{|c|c|c|c|c|c|c|c|}
\hline \multicolumn{2}{|c|}{ Psychotherapy experience } & \multirow{2}{*}{$\begin{array}{l}\text { Long-term } \\
95 \% \\
59 \%\end{array}$} & \multirow{2}{*}{$\begin{array}{l}\text { CBT } \\
73 \% \\
25 \%\end{array}$} & \multirow{2}{*}{ 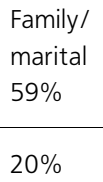 } & \multirow{2}{*}{$\begin{array}{l}\text { Group } \\
\text { therapy } \\
45 \%\end{array}$} & \multirow{2}{*}{$\begin{array}{l}\text { CAT } \\
41 \% \\
100 \%\end{array}$} & \multirow{2}{*}{$\begin{array}{l}\text { Brief focal } \\
\text { psychotherapy } \\
32 \% \\
14 \%\end{array}$} \\
\hline No cases & 1 & & & & & & \\
\hline & $2-3$ & $32 \%$ & $50 \%$ & $30 \%$ & $30 \%$ & & $14 \%$ \\
\hline & $10+$ & & & $40 \%$ & & & $14 \%$ \\
\hline \multirow[t]{3}{*}{ Duration } & $\leqslant 16$ Weeks & $5 \%$ & $68 \%$ & $40 \%$ & $44 \%$ & $22 \%$ & $71 \%$ \\
\hline & 16-26 Weeks & $10 \%$ & $21 \%$ & $20 \%$ & $44 \%$ & $67 \%$ & $29 \%$ \\
\hline & 26-52 Weeks & $20 \%$ & $5 \%$ & $40 \%$ & & $11 \%$ & \\
\hline \multirow{3}{*}{$\begin{array}{l}\text { Supervision } \\
\text { frequency }\end{array}$} & Fortnightly & $14 \%$ & $39 \%$ & & $10 \%$ & $33 \%$ & $14 \%$ \\
\hline & Monthly & & $6 \%$ & $15 \%$ & $20 \%$ & & \\
\hline & Other & $10 \%$ & & $31 \%$ & $10 \%$ & & \\
\hline \multirow[t]{6}{*}{ Supervisors } & Consultant Psychotherapist & $48 \%$ & & $8 \%$ & $8 \%$ & & $11 \%$ \\
\hline & Psychotherapist (non medical) & $30 \%$ & $18 \%$ & $8 \%$ & $23 \%$ & $45 \%$ & \\
\hline & Consultant Psychiatrist & $18 \%$ & $12 \%$ & $75 \%$ & $31 \%$ & $18 \%$ & $78 \%$ \\
\hline & Specialist Registrar & & $6 \%$ & & $8 \%$ & & \\
\hline & Psychologist & $3 \%$ & $59 \%$ & & $23 \%$ & $36 \%$ & $11 \%$ \\
\hline & Other & & $6 \%$ & $11 \%$ & $8 \%$ & $0 \%$ & \\
\hline
\end{tabular}

CBT, cognitive-behavioural therapy; CAT, cognitive-analytical therapy. 
7

original

papers for the figure of only 23 potential respondents. However, the extremely high response rate (95\%) ensures that the results are representative of this particular cohort. We deliberately excluded those trainees who did not pass the Part II exam, as members of this group left the rotation at different stages of their training and therefore might have had a different (probably less full) experience. For those who passed the exam in the more distant past, it might have been difficult to recall all details of their training. However, they accounted for this by indicating when it was the case.

The rotation is small and atypical, in that it mostly covers deprived inner-city areas with high rates of serious mental illness. We were therefore surprised by the results of this study. It was hypothesised that due to the demands of busy jobs, psychotherapy experience would be more patchy. It seems that (pivotal to psychotherapy) one or more individual long cases were taken on by all but one respondent, despite the trainees having to move base from one hospital to another. This was found to be a problem in at least one previous study (Hwang \& Drummond, 1996)

Considerable numbers of respondents took part in psychotherapeutically-orientated events outside the scheme; with courses being popular (e.g. family therapy, group therapy, introductory lectures to psychoanalysis). This is a reflection not only of the special interest in the subject, but also the fact that the rotation, being so centrally placed, made it physically relatively easy for the trainees to get to various venues. The fact that the trust was supportive in facilitating 'study leave' is also not to be underestimated.

A large number of our respondents found a support group helpful; as these are now taking place at only one of three of our centres, this is an area for improvement, especially as the College recognises the importance of occupational stress among psychiatrists and recommends that adequate support networks should be made available to trainees (Grant et al, 1993). Unusually high numbers of trainees chose child and adolescent psychiatry as a career, and we speculate as to the relationship between this career choice and their early interest in psychotherapy. However, $63 \%$ of respondents have chosen specialities that are not immediately linked with psychotherapy. Nonetheless, the majority still showed a strong interest in it, valued it highly and wished for it to be a larger part of the curriculum in both theory and clinical experience. It seems that the psychotherapy experience is helping them to become more psychologically orientated psychiatrists, without necessarily 'turning them' into Consultant Psychotherapists.

\section{Conclusion}

The study shows that in this particular rotation in East London, there was a high level of psychotherapy experience, both didactic and case work, during the period of 1993 to spring 2001. In a previous paper, it has been noted that for comprehensive psychotherapy experience to be gained at SHO level, a willingness and availability on behalf of both supervisors and supervisees are essential (Wildgoose et al, 2002). It seems that although it is not the easiest option, it is possible to fulfil some of the College guidelines even with a relatively understaffed and poorly-resourced service, compared with an ideal setting that provides ring-fenced time, multiple psychotherapy consultants and comprehensive theoretical training. The new College requirements set explicit standards in psychotherapy training that are mandatory at the level of the individual MRCPsych candidate and at the level of the training courses. It appears that the rotation described in this paper does have a good foundation on which to implement these requirements.

\section{Acknowledgements}

We would like to thank all the former trainees for completing the questionnaires and especially for their additional comments, DrTim Read (clinical tutor) for identifying our responders and Timothy Eyres for his IT support in analysing the responses.

\section{References}

BYRNE, P. \& MEAGHER, D. (1997) Psychotherapy and trainees. Psychiatric Bulletin, 21,707-710.

GRANT, S., et al (1993) Guidelines for psychotherapy training as part of general psychiatric training. Psychiatric Bulletin, 17, 695-698

HAMILTON, R. J. \& TRACY, D. (1996) A survey of psychotherapy training among psychiatric trainees. Psychiatric Bulletin, 20, 536-537.

HWANG, K. \& DRUMMOND, L. M. (1996) Psychotherapy training and experience of successful candidates in MRCPsych examinations. Psychiatric Bulletin, 20,604-606.

*M. Podlejska-Eyres Specialist Registrar in Psychotherapy, Tavistock Clinic, 120 Belsize Lane, London NW3 5BA， J. Stern Consultant Psychiatrist in Psychotherapy, St. Marks Hospital, Harrow
ROYAL COLLEGE OF PSYCHIATRISTS

(2001) Requirements for psychotherapy training as part of Basic Specialist Psychiatric training (unpublished).

ROONEY, S. \& KELLY, G. (1999) Psychotherapy experience in Ireland. Psychiatric Bulletin, 23, 89-94.

WILDGOOSE, J., MCCRINDLE, D. \&

TILLETT, R. (2002) The Exeter half-day release psychotherapy training scheme - a model for others? Psychiatric Bulletin, 26, 31-33.

Bull

